\title{
Fatigue loading characteristic for the composite steel-concrete beams
}

\author{
Ahmed I. Hassanin \\ Egyptian Russian University, Egypt \\ Ahmed_eng8028@yahoo.com,ahmed-ibrabim@eru.edu.eg, bttp://orcid.org/0000-0002-5606-3065
}

Hesham M. Fawzy

Zagarig University, Egypt

hmshaban@eng.zu.edu.eg

\author{
Ahmed I. Elsheikh \\ Liverpool University, UK. \\ abmed.elsheikh@liverpool.ac.uk
}

\begin{abstract}
In the last few decades, composite beams, steel I beam, and concrete slab, have had a wide range of usage in bridges construction. This is due to its relatively low economic constructional cost compared to individual steel structures or reinforced concrete structures. This type of bridges in particular and many similar industrial structures in general are repeatedly subjected to fatigue loads, and that is frequently, as a result of the vehicles passing on these bridges or the vibrations caused by the machines in the industrial facilities. Previous investigation of fatigue behavior of composite steel-concrete structures has become ever more important, specially, steel concrete composite beams. These studies focused mainly on the external structural behavior of these beams such as a load -deflection relation, observing of cracks appeared during the loading and failure stage, and the strain in the steel and concrete flanges. Hence, in this study several factors affecting the mode of failure of these beams under the fatigue loads. ANSYS (Workbench) software package was used to construct a finite element model subjected to cyclic loading, and obtain members' cyclic behavior at a positive bending moment area. The results of the F.E. analysis were compared with experimental tests to obtain the validity of the finite element model and its accuracy. A parametric study was also conducted to investigate the effect of varying degrees of shear connection on the cyclic loading performance for each part of the composite section.
\end{abstract}

KEYwORDS. Composite beams; Cyclic loading; Fatigue loads; F.E.M.; Shear connection.

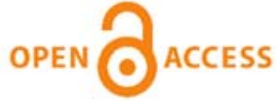

Citation: Hassanin, A.I., Fawzy, H. M., Elsheikh, A. I. Fatigue loading characteristic for the composite steel-concrete beams, Frattura ed Integrità Strutturale, 55 (2021) $110-118$.

Received: 09.09.2020

Accepted: 05.11.2020

Published: 01.01.2021

Copyright: (C) 2021 This is an open access article under the terms of the CC-BY 4.0, which permits unrestricted use, distribution, and reproduction in any medium, provided the original author and source are credited. 


\section{INTRODUCTION}

$\mathrm{R}$

ecently, steel- concrete composite beams have been widely used in building and bridge construction. The advantages of these beams in comparison to traditional reinforced concrete girders can be clearly seen in their ability to bend and stiffness. This is due to the benefits of the composite action, which is achieved by connecting the concrete slab and steel section and utilizing the speed of manufacturing time. Recently many steel-concrete composite structures failed to meet their functional and structural requirements, which was a result of corrosion and enlarged cracks resulting from fatigue caused by the dynamic loads of vehicles moving on bridges, and insufficient maintenance. The use of steel-concrete composite girders that were created in real building structures started in the 1950s, noting the phenomenon of fatigue failure, gained the attention of the designer and research community. The main member of the steel concrete composite girders is shear connectors and the type commonly type used is a shear stud. Therefore, most of the research conducted on the cyclic and fatigue loading response of the steel-concrete composite girders had focused attention on the structural behavior of the shear connectors.

Slutter and Fisher [1] performed fatigue loading tests on shear connectors and identified the welding surface between the steel top flange and shear connectors as the fatigue failure region. The tests led to a relationship between the shear stress acting on connectors and the number of loading cycles. Furthermore, they proposed the "S-N" method as the most reliable for determining the shear connectors' fatigue life. Later, R.P. Johnson [2] used experimental data on composite beam fatigue tests to predict the fatigue life of shear connectors:

$$
\lg (\mathrm{N})+8 \lg (\Delta \tau)=22.123
$$

where $\mathrm{N}$ is the number of cycles. This expression was later adopted by Eurocode 4[3].

However, obtaining this equation was under the base of big experimental data's number of and also under consideration of the guaranteed rate, so it was well suited for designers. Paul Geundy and Geoff Taplin [4] investigated the effect of cyclic load (monotonically) and fatigue load (reversely) on cumulative slippage at the surface between the steel top flange and concrete slab. They concluded that monotonic cyclic loading caused much slower growth in slippage than cyclic reversed fatigue loading.

After 10 years, Hanswille et al. [5], presented an equation to predict the growth in residual slippage with the number of loading cycles. Follow-up research identified three stages, in which residual slip grows with loading cycles. The first stage involved fast growth in the residual slip followed by a stage of slow and stable growth before experiencing again fast growth in residual slip, which continued until failure [6-8]. In 2014 Wang Yu-Hang et al. [7] Performed fatigue analysis to study the performance of composite steel-concrete beams and shear connectors. Seven beams were test to study the fatigue behavior of shear connectors in composite steel-concrete beams. Shear fatigue failure of shear connectors was the failure mode for the tested beams. Shear stress amplitude of shear connectors was a significant factor affecting the fatigue life of tested beams. Then proposed mathematical calculations were presented to determine the deflection of the beams. So more than that, they decided to analyze more influence various parameters focused on the deflection of composite steel-concrete beams subjected to fatigue load.

Recently, Hassanin et al.[9] conducted a numerical study on a large number of composite beams models under the influence of fatigue loads. During this study, they focused on several variables, the most important of which was changing the number of the shear studs, which results in changing the degree of shear connection of the concrete slab with the steel section. The study was also advanced in terms of interest in representing the welding region for studs. Where a wild collar with a material similar to that reality.

In this study, attention will be focused on two main points that most previous numerical studies have overlooked, namely the study of the form of failure at the weld region in the longitudinal section and the cross section of the stud. The second point is about the change in the shape of the failure in this region when changing the degree of shear connection between the concrete slab and the steel section.

After these previous studies, the main objective of this study is to provide FEM of nonlinear and material modeling of composite beams. These composite beams will be examined and studied under fatigue loads to observe failure patterns of the welding area between shear studs and the steel beam. Also, these beams will be tested on different degrees of composite interaction starting from $40 \%$ to $100 \%$ (full shear interaction). The focus will be on specific results that were not taken into account in previous studies such as the mechanical performance of shear connector at failure and the ratio of stud forces to its relative position as a strong indicator of the degree of weld tolerance at the failure stage. Fig. 1 shows a flow chart clarify the proposed numerical analysis work in this study. 


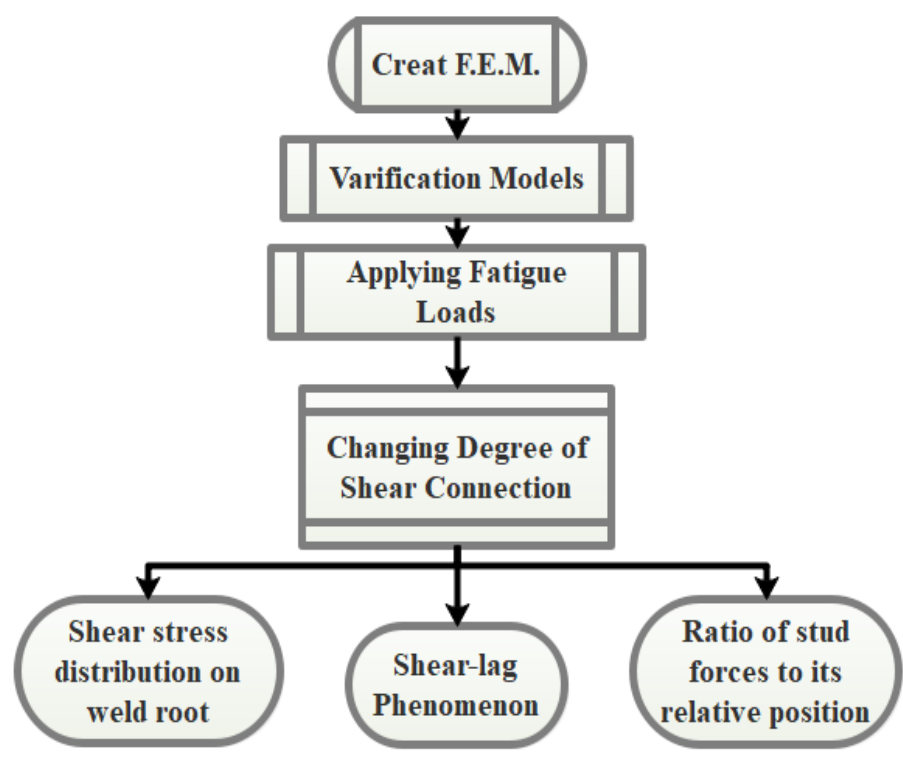

Figure 1: Proposed numerical analysis work in this study

\title{
NUMERICAL SimULATION
}

\begin{abstract}
A
non-linear analysis of 3D finite elements (FEA) of composite beams was carried out using the software program ANSYS (Workbench V.19.2). For the simulation of concrete, a 3D brick element with 8 nodes (SOLID65) was chosen, Fig. 2. This element is suited for the representation of cracks, crush failures, and shear transfer of concrete after cracking. Shell element (SHELL181) was used to model steel components with four nodes per node with six degrees of freedom. Unlike most previous studies, that used single-line elements to model shear connectors, shear connectors in this study were simulated as a 3D body element (SOLID45) with two parts representing the stud body and the stud root and connected to a bonded connection (welding collar was assumed to be brittle)[9-11]. Steel re-bars have been modeled using 3D link elements (LINK8-an element with two nodes and three degrees of freedom per node, which can model plasticity with large deflection). To represent the interface between the steel top flange and the concrete slab, node-to-node contact elements (CONTAC52) and unidirectional spring elements (COMBINE39) were chosen. The contact element will support tangential friction and compression to connect in the normal direction. The reason for using this element was to prevent surface penetration and ensure a physical separation of the steel and concrete components.
\end{abstract}

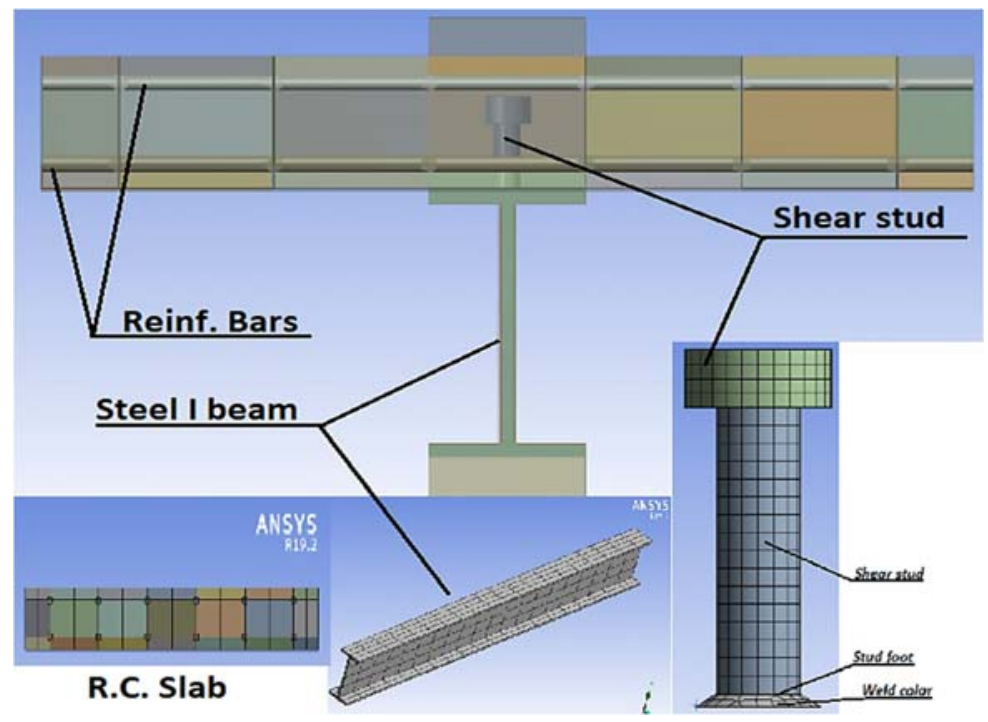

Figure 2: The finite element model used in the study. 


\section{MOdel VALidation}

$\mathrm{I}$ $\mathrm{n}$ this part, the validity of the FEM was checked in comparison with the experimental results obtained from two previous studies. The results were included in the first study of a beam (FSCB-2) tested by Yu-Hang et al. [7]. This was especially relied upon due to the availability of full details for this test. The model predictions were consistent with the experimental results, except that it was about 7\% stiffer in the linear and nonlinear behavior stages. The reason for this difference is attributed to the assumption of complete bonding between concrete and steel reinforcement in the concrete slab.

The second experimental study that was relied upon as one of the push-out tests performed by Ovuoba and Prinz [12] (Slab 2 of Specimen 1). It was taken into consideration during the verification process in order to assess the slip representation quality of the composite beam between the steel section and the concrete slab under fatigue loads. The results were consistent between the FE model and the experimental data, with the observation of greater stiffness in the linear model by about $9 \%$ in the linear phase. This stiffness may be attributed to the compatibility bonding between the shear studs and the steel section. This difference continued to grow until failure took place at $13 \times 10^{6}$ cycles.

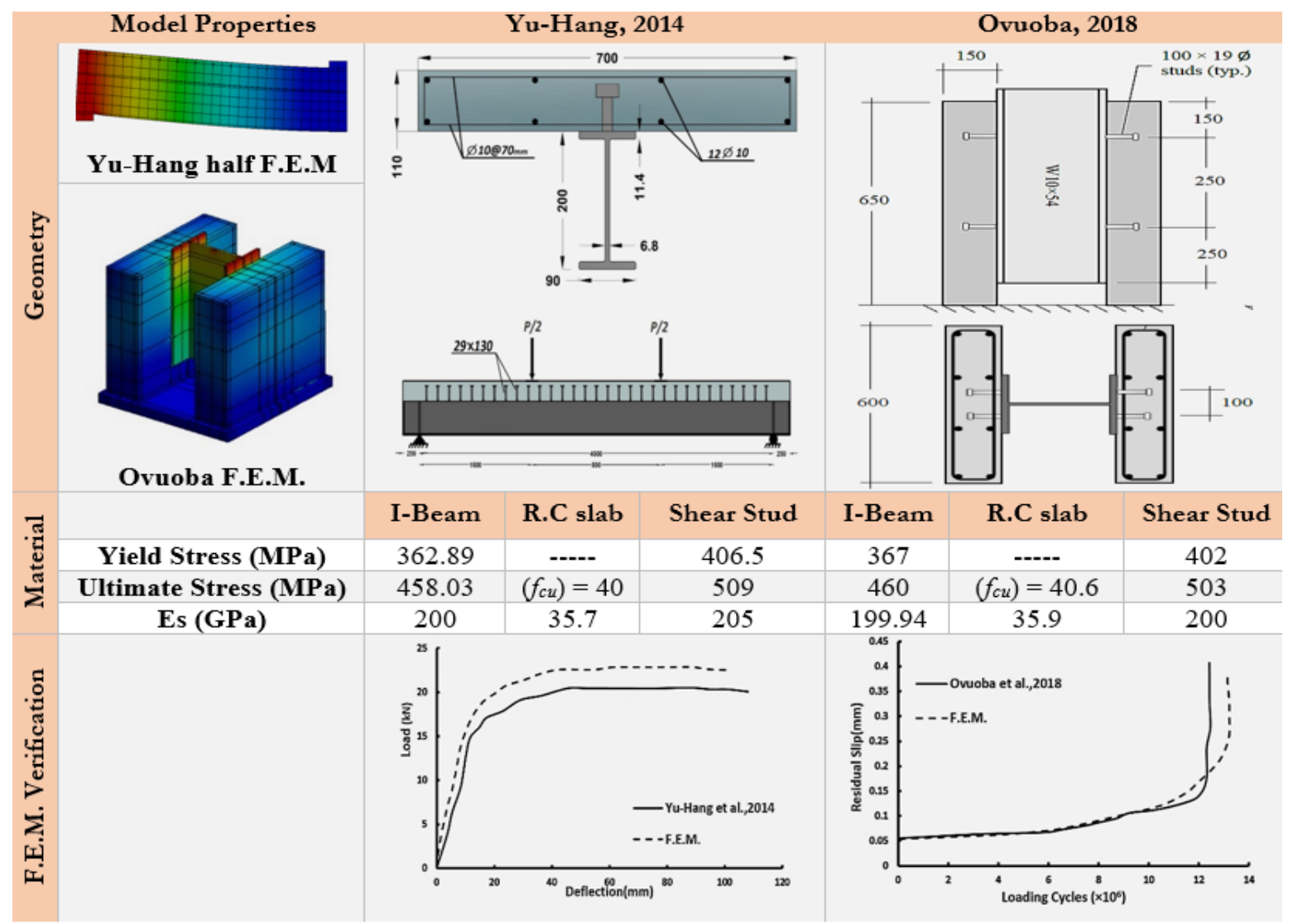

Figure 3: Details of validated models

\section{PARAMETRIC STUDY}

S even models in terms of degree of shear connection divided into seven degrees (from $40 \%$ to full shear connection with $10 \%$ increment in the degree of interaction). In each type of these models, There were two loading intervals; interval 1: sinusoidal waveform fatigue loading with a constant amplitude [7]. The repeated load $\mathrm{P}_{\mathrm{r}}$ (which will be located in rang between $\left(\mathrm{P}_{\max }\right.$ and $\left.\mathrm{P}_{\text {min. }}\right)$ ) Will be determined using the beam initial cracking load $\left(\mathrm{P}_{\mathrm{cr}}=\mathrm{P}_{\max .}=\mathrm{P}_{\mathrm{u}} / 3\right)$. A residual static loading stage will be performed on models that did not suffer fatigue failure after repeated cycles of $2.5 \times 10^{5}$. Interval 2: The residual static loading following fatigue failure of the beam will be reloaded with a static load to obtain its residual static capacity. Fig. 4 shows the used cyclic loading pattern. 
The range of fatigue loads for shear connectors was obtained from the shear stress number of $118 \mathrm{MPa}[13]$ and according to AASHTO specification [14] and European standards [15]. The average fatigue load was derived from the analyzed shear connector 's 30\% static shear strength [16]. This can be considered a high cyclic fatigue load pattern with an average fatigue life over one million cycles. By adjusting the total number of shear connectors over the span length, we can control the degree of shear interaction [9,17]. For the effect of the shear interaction between the top flange of the steel beam and the concrete slab on the overall behavior of the composite beam, seven beams with seven different degrees of shear connection were evaluated under named sections $((\mathrm{HB}-\mathrm{N})$ where $\mathrm{N}$ was the degree of interaction as a percentage from full shear interaction case). The parametric analysis was summarized in detail in Tab. 1.

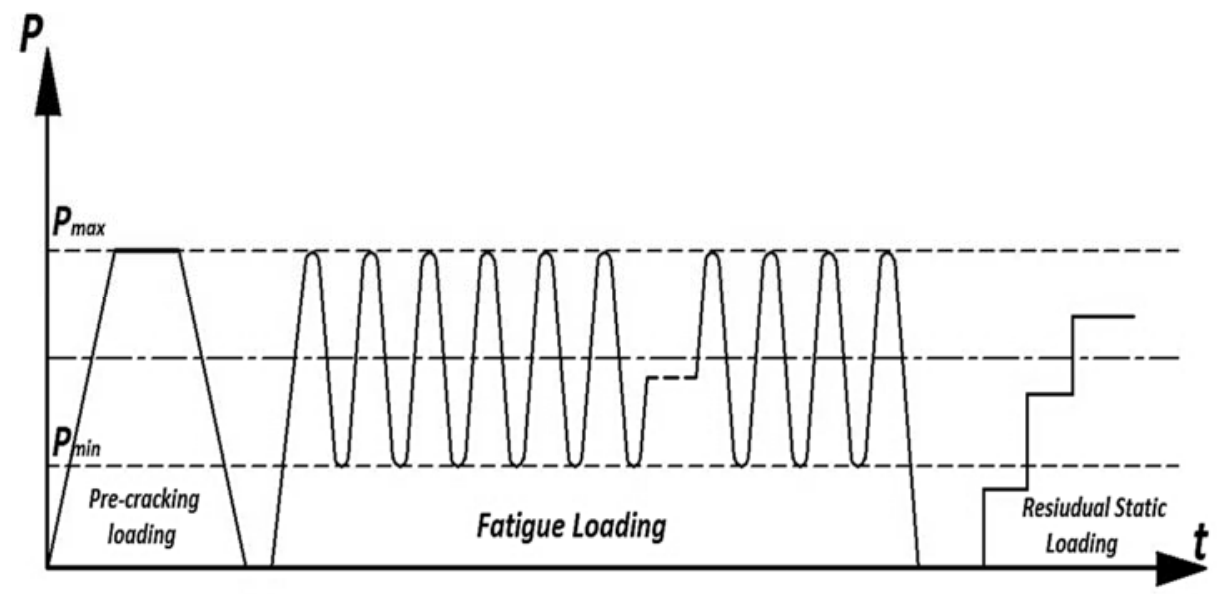

Figure 4: Used cyclic loading pattern [9].

\begin{tabular}{ccccccc}
\hline Beams & $\begin{array}{c}\text { No. of } \\
\text { studs }\end{array}$ & $\begin{array}{c}\text { Shear studs } \\
\text { spacing(mm) }\end{array}$ & $\begin{array}{c}\text { Degree of } \\
\text { Interaction } \\
\mathbf{( \% )}\end{array}$ & $\begin{array}{c}\text { Cyclic load (kN) } \\
\text { Upper limit } \\
\left(\mathbf{P}_{\text {max. }}\right)\end{array}$ & $\begin{array}{c}\text { Lower limit } \\
\left(\mathbf{P}_{\text {min. }}\right)\end{array}$ & Amplitude \\
HB-100 & 29 & 138 & 100 & & \\
HB-90 & 26 & 153.8 & 90 & & \\
HB-80 & 23 & 173.9 & 80 & & \\
HB-70 & 20 & 200 & 70 & & \\
HB-60 & 17 & 235.3 & 60 & & \\
HB-50 & 15 & 266.7 & 50 & & \\
HB-40 & 12 & 333.3 & 40 & & \\
\hline
\end{tabular}

Table 1: Used models and analyzed parameters in this study.

\section{ANALYSIS OF THE OBTAINED RESULTS}

\section{Mechanical Performance of shear connector failure:}

$\mathrm{W}$

hen the shear connector was finally broken, the crack shape had a crescent shape [11]. The simplification of the crack shape in the F.E. analysis as an even flat and the change rule in sectional geometry features of the shear connector was shown in Fig. 5. It can be seen that at the beginning of the fatigue load, the crack is small and the sectional geometry feature displayed with small change, but after proceeding into a large number of cycles (more than $30 \times 10^{4}$ cycles) there were be a big change shown in increasing in deflection, small cracks noticed in concrete slab around shear connectors foot propagation and overall sectional composite action. At low degrees of shear connection models (HB60 and HB-40) there was a shear force redistribution in the interface from shear connectors with larger damage to those with smaller damage that occurred with a fast clang in every loading cycle. So, the conclusion about cumulative slippage, deflection, and composite action loss, controlled by the reduction in the interface bond or connection, and occurred due to the increasing of repeated load cycles [12]. 

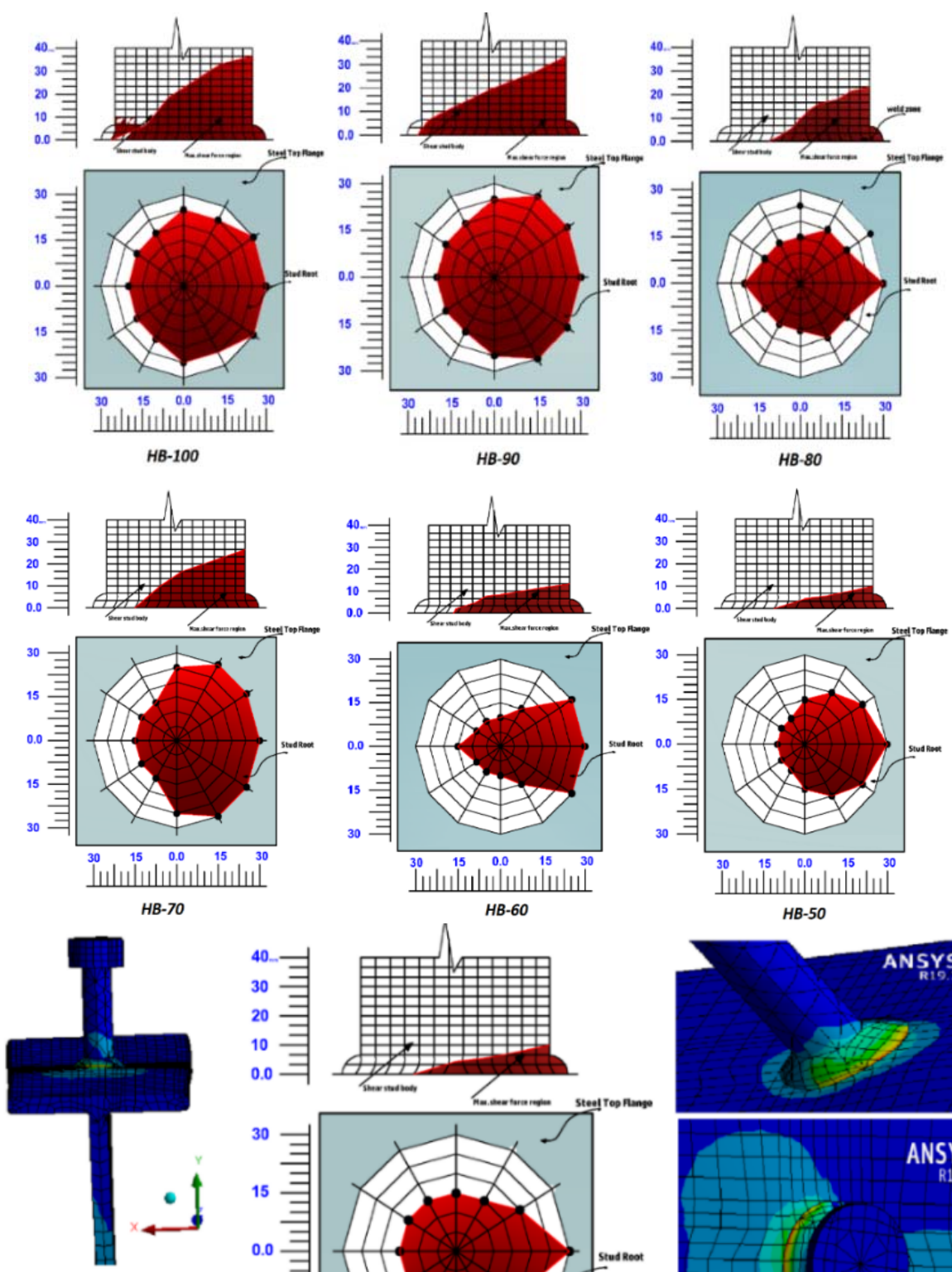

Max.Shear stress on Stud
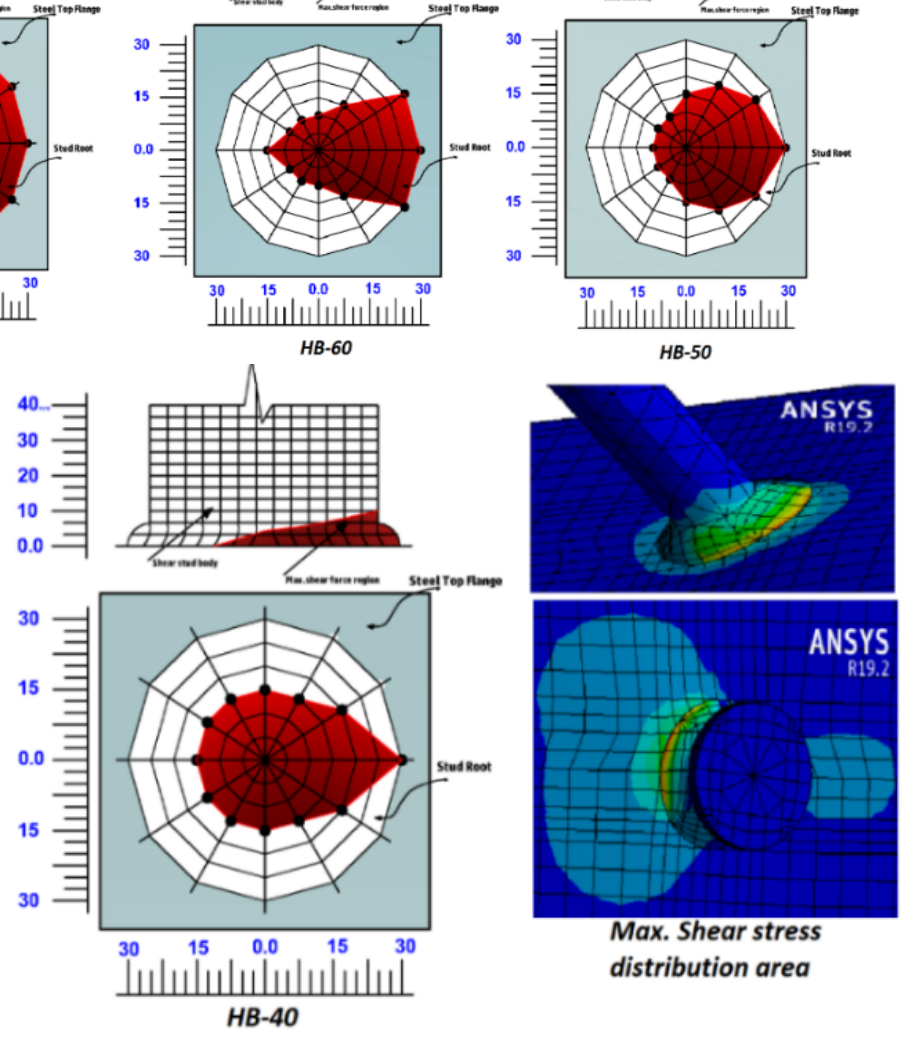

Max. Shear stress

distribution area

Figure 5: The maximum principal shear stress distribution around stud root.

Strain changes at mid-span of beams:

To assess the strain on the steel beam at various points in the steel beam section and to evaluate the incidence of a shearlag phenomenon in the contact region between the steel beams and shear connectors. For steel beam, strain values were detected, as shown in Fig. 6. There was a linear strain distribution along the steel beam section but there also seems to be some irregularity of strain continuity at the interface between the top flange of the steel compression surface and the shear connectors. According to the last findings, the shear lag phenomenon had already occurred and had a strong impact on the welding region between the body of the shear connectors as a target element and the steel beam top flange. Furthermore, it is the subject of future studies on strengthening this region for better performance of shear stud resistance. The indication of the assumption that plane sections remain plane $[9,10]$ was also agreed well with the used steel cross-section. 


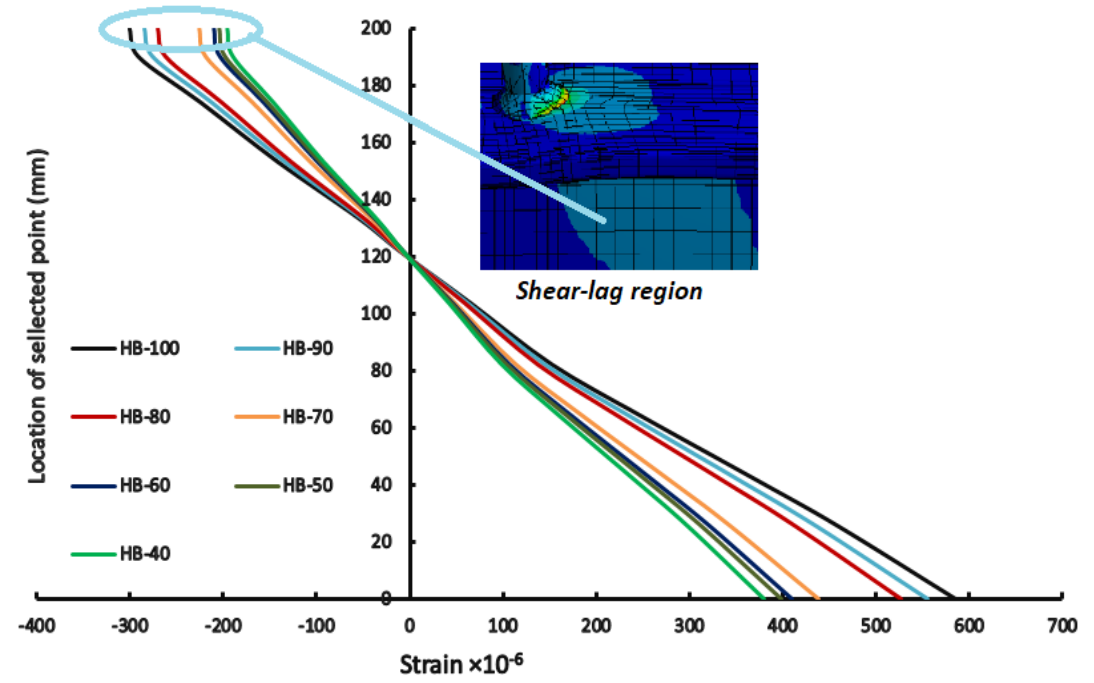

Figure 6: Strain changes at mid-span of the tested beams.

\section{Ratio of Stud Forces to its Relative Position}

From Fig. 7, and based on the strength of the concrete slab, steel beam, and shear studs. By comparing the minimum and maximum bearing capacity of the studs along beam span $(\mathrm{L})$, the following was noted: The slippage reaches its maximum value at the of the maximum shear force region (supporting points at this case), and these forces on the studs gradually decrease until they reach their lowest level at the zero points (between the two loading points (starting from 0.4 span length)). However, the value of the shear force affecting studs does not reach zero in this region, and the reason for this is due to the momentum resulting from the transmission of the shear force between studs along the length of the composite beam. On the other hand, a widening of the difference in the bearing capacity of the studs between the beams under different degrees of shear connection was noticed. The tested beams were divided into two groups according to the degree of shear connection.

The first group from the lowest degree of shear connection value, from $(40 \%)$ to $(70 \%)$, and the value of the shear force was large on most studs along beam span, as a result of partial loss of composite action at the beginning of the loading stages, which ended with the loss of this composite action later before the failure occurred. The second group was from $(80 \%)$ to $(100 \%)$ degree of shear connection and the degree of influence on the studs was less severe, which gives the first impression that it is not allowed to reduce the shear connection degree in any way from $80 \%$ in the composite beams in order to avoid premature loss of composite action.

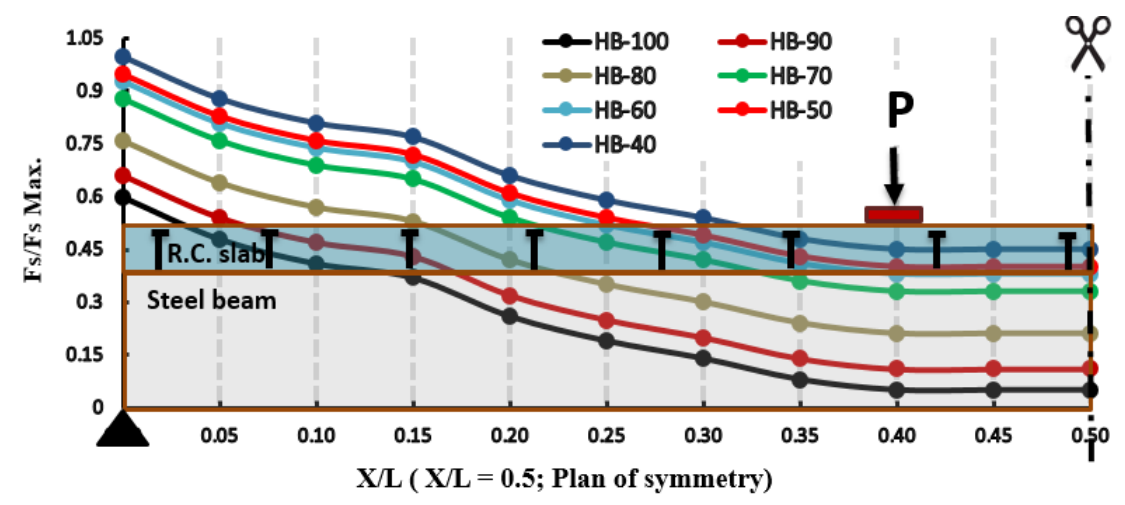

Figure 7: Ratio of stud forces to its relative position.

\section{CONCLUSIONS}

$\mathrm{I}$ $\mathrm{n}$ this paper, the main purpose was to study the effect of fatigue loads on the failure shape in the weld region of the shear studs used in the composite beams. This study was carried out using nonlinear analysis of finite element modeling. By using the results of previous experimental tests, the validity and efficiency of the model used to extract results 
consistent with the experimental results were verified. A study was also conducted on the effect of changing the degree of shear connection between the concrete slab and the steel beam, and some conclusions were reached:

1) A good compatibility has been reached between the model used by the finite element method and previous experimental test data, this compatibility ensures the validity of the model in predicting and analyzing the behavior of the composite beams under the influence of fatigue loading with different shear connection degrees.

2) Based on the results obtained, it is preferable that the value of the degree of shear connection during fatigue loading is not less than $80 \%$ in order to avoid premature loss of composite action and thus reduce the fatigue life of the beam.

3) In cases of shear connection levels greater than $80 \%$, the failure mode of the beam was fatigue cracking along the weld area when the upper fatigue limit equaled a value higher than $56 \%$ of the final load.

4) At shear connection levels below $80 \%$, the mode of failure in the weld zone was more severe due to the premature loss of composite action. Therefore, care should be taken to strengthen this area or be careful not to be loaded in low-levels of shear connection.

5) The distribution of shear forces resulting from loading is subject to the momentum created by the presence of the studs in a number that allows them to resist these forces. Therefore, it is not possible to neglect the studs in the zero share areas.

\section{Data Availability Statement}

ome or all data, models, or code that support the findings of this study are available from the corresponding author upon reasonable request.

\section{CONFLICT OF INTEREST STATEMENT}

$\mathrm{O}$

$\mathrm{n}$ behalf of all authors, the corresponding author states that there is no conflict of interest.

\section{REFERENCES}

[1] Slutter, R.G., Fisher, J.W. (1966). Fatigue Strength of Shear Connectors, 45th Annu. Meet. Highw. Res. Board, 315(147).

[2] Johnson, R.P. (2000). Resistance of stud shear connectors to fatigue, J. Constr. Steel Res. DOI: $10.1016 /$ S0143-974X(99)00082-6.

[3] (2004). Designers' Guide to EN 1994-1-1: Eurocode 4: Design of Composite Steel and Concrete Structures, Part 1-1: General Rules and Rules for Buildings, .

[4] Geoff T, P.G. (1997).Incremental slip of stud shear connectors under repeated loading. Composite constructionconventional and innovative, Innsbruck, Austria, pp. 145-50.

[5] Hanswille, G., Porsch, M., Ustundag, C. (2007). Resistance of headed studs subjected to fatigue loading. Part I: Experimental study, J. Constr. Steel Res., DOI: 10.1016/j.jcsr.2006.06.035.

[6] Hanswille, G., Porsch, M., Ustundag, C. (2007). Resistance of headed studs subjected to fatigue loading, J. Constr. Steel Res., DOI: 10.1016/j.jcsr.2006.06.035.

[7] Yu-Hang, W., Jian-Guo, N., Jian-Jun, L. (2014). Study on fatigue property of steel-concrete composite beams and studs, J. Constr. Steel Res., DOI: 10.1016/j.jcsr.2013.11.004.

[8] Wu, G., Wang, H., Wu, Z., Asce, M., Liu, H., Ren, Y. (2012). Experimental Study on the Fatigue Behavior of Steel Beams Strengthened with Different Fiber-Reinforced Composite Plates, (May), pp. 127-137. DOI: 10.1061/(ASCE)CC.1943-5614.

[9] Hassanin, A.I., Shabaan, H.F., Elsheikh, A.I. (2020). The Effects of Shear Stud Distribution on the Fatigue Behavior of Steel - Concrete Composite Beams, Arab. J. Sci. Eng., DOI: 10.1007/s13369-020-04702-4.

[10] Hamilton, R., Tennyson, S., Hamilton, W. (2001).Analysis by the transformed-section method. ASEE Annual Conference Proceedings. 
[11] Wang, J., Guo, J., Jia, L., Chen, S., Dong, Y. (2017). Push-out tests of demountable headed stud shear connectors in steel- UHPC composite structures, Compos. Struct., 170, pp. 69-79, DOI: 10.1016/j.compstruct.2017.03.004.

[12] Ovuoba, B., Prinz, G.S. (2018). Investigation of residual fatigue life in shear studs of existing composite bridge girders following decades of traffic loading, Eng. Struct., DOI: 10.1016/j.engstruct.2018.02.018.

[13] Ovuoba, B., Prinz, G.S. (2016). Fatigue Capacity of Headed Shear Studs in Composite Bridge Girders, J. Bridg. Eng., DOI: $10.1061 /$ (ASCE)BE.1943-5592.0000915.

[14] AASHTO. (2012). AASHTO LRFD bridge, ProQuest Diss. Theses, , pp. 1661.

[15] Navr, J. (2014). Eurocode Design Of Composite Concrete, (1), pp. 1-6.

[16] Xu, C., Sugiura, K., Su, Q. (2018). Fatigue Behavior of the Group Stud Shear Connectors in Steel-Concrete Composite Bridges, J. Bridg. Eng., 23(8), DOI: 10.1061/(ASCE)BE.1943-5592.0001261.

[17] El-zohairy, A., Salim, H. (2017). Parametric study for post-tensioned composite beams with external tendons. DOI: $10.1177 / 1369433216684352$. 